\title{
Authenticity versus hybridity in rural Greece
}

\author{
A.-M. Theodoraki ${ }^{1}$, J. Theodoraki-Patsi ${ }^{2}$ \& P.-C. Theodoraki ${ }^{3}$ \\ ${ }^{1}$ Bartlett School, University College, London, UK \\ ${ }^{2}$ National Technical University, Athens, Greece \\ ${ }^{3}$ Architectural Association, London, UK
}

\begin{abstract}
The architectural representation of diverse rural settlements in the Serres district (northern Greece) originated from different periods of the 20th century. The history of the region describes authenticity in some cases in contrast with hybridity and heritage development in others. Architectural heritage (in all closely related aspects) is important in restructuring rural space. The local identity, especially, that which emerges from the various historical pathways of each region, constitutes today one fundamental perspective for local sustainable development. Rural development promoting a local identity is related also to the "third wave" of development, the "informational", contributing to the rehabilitation of architectural heritage in order to promote tourism.

Most of the traditional architectural morphology of the Serres district was destroyed during the First World War and later the area had to settle 135,000 Greek refugees from Asia minor in new rural settlements according to the treaties of Neuilly and Lausanne. In the $50 \%$ of settlements that have been implemented for the refugees between 1923 and 1940, the "making" of the built environment is documented. In Greece, the dichotomy between natural or systematic land distributions is recorded since antiquity. During the Byzantine era and later on during the Ottoman occupation the land management followed natural distributions. The natural distribution for Greece corresponds to the term "traditional", a heritage from the period before the 20th century. Systematic distributions were implemented after 1923, when the district became part of Greece and they correspond to the term "planned".

In the three dimensions, the diversity of architectural elements in the Serres district, describes the inter-crosses between the traditional, the neoclassical symbolism and the modern movement, followed by the current regeneration of the local identity issue in rural areas as initiative for sustainable development. The revival of traditional values questions, once more, authenticity or hybridization, while virtual reconstructions and databases of threatened cultural heritage support the context of the new place making.

Keywords: traditional architecture, heritage, identity, hybridity, authenticity, rural, sustainable development, rehabilitation, representation, Serres.
\end{abstract}




\section{Terminology}

The terms in use remain very complex concepts and are used in a variety of ways. Examination of their dictionary definition or derivation is useful as much as their interpretation for the present purpose.

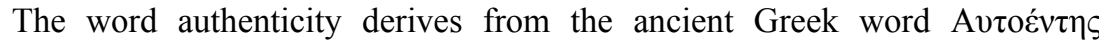
(Aphtoentis) meaning the person who acts upon authority which corresponds to the English master. Authenticity in architecture is interpreted as the undisputed prototype, the archetype and the master-piece. The coding of prototypes demarcates the architectural norms (Oliver [1]) and types as well as the historical courses of every "authentic" tradition located in the realm of identity. Tradition is the evidence of continuity of identity through time. Authenticity is a desirable quality of tradition while tradition is a commodity.

The term hybridity derives from biology and the Darwinian evolutionary theory (Gould [2]) of species dictating "that crosses between varieties of a species are usually fertile, but crosses between species are generally sterile". When this statement is applied to the built environment it means that in the long run what is impaired for a culture vanishes. Mean while intensified contact between cultures institutes a period of hybridity. Hybridity in this context is present in every transitional period of intersection between cultures. The latest period of hybridity is the current one with instant communication crossing multicultures. An intercourse is emerged between local population possessing the individuality of architectural heritage as an economic commodity and the consumers of instant communication in search of their individuality. A new hybridity arises.

From the spectrum of the meanings of the term "identity" it is used the notion that perceive identity as a social good structured according to the specific historical paths (Council of Europe [3]) of each region. From the historical context the "desired" collective memory "is selected and projected" onto the built environment, in respect to the symbolism of the architectural heritage in favour. In times of conquest, the dominant nation imposes the architecture that expresses it, which consequently results in the coexistence in the same place of monuments and premises of diverse historical origin that compile the architectural heritage, wherefrom prevalent representations are selected in later times of development. The emergence of identity is a very complex phenomenon related to perception, images and interpretations.

Sustainable development as all the previous notions is a neology and in fact the latest. According to the European Union statement sustainable development means to meet the needs of the present generation without compromising the ability of future generations to meet their own needs. Sustainable development is about safeguarding the earth's capacity to support life in all its diversity. It is based on democracy, gender, equality, solidarity, the rule of law and respect for fundamental rights.

This statement simplified means to improve living and working condition without damaging the environment. Management of authentic traditional 
architecture promotes development and benefits rural communities increasing employment and attracting tourism.

The term "rural" describes the historical interaction between natural resources and human ways of appropriating them and that beer witness to the coherent hybridization of the biophysical factors of a region and the socioeconomic factors of the community that inhabit it (Rehabimed [4]). In the present paper the dimension and divers meaning of the term "rural" interest in the codification of norms for the local identity for settlements with a population inferior to 2000 inhabitants, a population that in Greece is counted as rural.

\section{The "making" of Serres district}

The development of Serres district was centered in a rural perspective while the context of place-making evolved during the span of a century, documenting the divers phases of the cultural diversities projections on the built environment.

During the 19th century, Northern Greece was traditionally rooted on an eastern (Ottoman) pattern. In the beginning of the 20th century, after the First World War and throughout the span of a generation, it was transformed to an integral and productive part of the modern Greek nation. The major factor affecting this transforming process was a series of ethnic migrations between Greece, Turkey and Bulgaria commencing in 1912 and culminating in an official exchange of minorities population under which a number of people was "required" to settle. In the frame of successive annexation of territories in the modern Greek state, the limits of Serres district were fixed in 1912 with the Treaty of Neuilly. In 1923, by the Treaty of Lausanne the population increased by $64,54 \%$ and new settlements were planned for the Greeks that resorted in the region under the regulations of the exchange of population. The increase of population was also continued in the interval between the two Wars by $24,76 \%$, while since and up to the last decade, it presents decrease with a small flash at the decade of $50 \mathrm{~s}$.

Until the beginning of 20th century, 59 "kefalochoria" and 56 "tsiflikia" (tsiflikia is the Greek term for capital village and Ottoman term for the exploitation unit that correspond to term farm. In 1917 the provisional government of Thessaloniki with five legislative decrees (2466-2470), it imposed distribution of 56 "tsiflikia" in the villagers, that with the redistribution that followed, they acquired privately-owned agricultural land) existed in the region. Most residents lived in very poor conditions and they abandoned the region, so that, in the beginning of the century the density of population was only 10 res. $/ \mathrm{km}^{2}$. The Greek origin population prevailed, but a lot of minorities existed: Slavs, Muslim (the Mouslim population was distinct, but there was a conflict between the Christian population (Bulgarians and Greeks) for the character of certain villages, see Yeager [5]), Gipsy, Vlahi (Abbot [6]) and Bulgarians. The most over-populated area of the district was in the foot of mount Menikion, where the villages by the name Darnacochoria remained Greek speaking during all the Ottoman domination (since antiquity, The Agriones (warriors of Alexander the Great) had lived in the same region, as proven by the 
name of a local area (Agriansta); Psathas [7]). During the First World War and the 2nd Bulgarian possession the valley of Strymon river, suffered enormous destruction.

With the exchange of populations, after the end of the First World War, the Greek character of the district was reinforced and the population increased so, that in 1926 , the density reached $46,48 \mathrm{res} . / \mathrm{km}^{2}$. At the same time, hydraulic and irrigation network for the control of the river Strymon - which flooded and destroyed the plain - was constructed contributing to the increase of agriculture. The demographic development in the period between the two World Wars reflects the degree of installation of new population (the following numbers show the size of changes in the Northern Greece: Number of new households 130,623, new settlements 1,407; see Bouazoglou [8]). The settlements were increased in number and changed name and place. The settlements that were designed for the refugees were placed mainly in the plain and their design was worked out by Greek and foreign architects under the guises of a special international Committee for the Rehabilitation of Refugees (C.R.R.). Very little was applied (Ministry of Transport [9]) though because the Greek Ministry of Agriculture took charge and new studies with rectangular "hippodamian" distributions were followed. Where possible the new residents installed themselves in abandoned residences, but most inhabited new settlements. The exploitation of land was shaped in very small lots of 2-3 hectares, which were not economically liable, and later led to high indicators of immigration. The irrigation work that began in 1930, increased the agriculture in the plain, while new cultures and techniques, were inaugurated.

During the 2nd World War, 25\% of the district settlements were destroyed. The destruction continued after the war, during civilian war, with the abandonment of mainly mountainous settlements and the immigration to the urban centers. After the 2nd World War, new settlements were planned and at the same time the road network was extended and renew.

The new settlements that have been created since then are minimal, with the exception of some "arbitrary" resettlement constructions from people who abandoned mountainous settlements, for places near the plain that offered employment in rural industry and transports.

In the last decade, some new population is recorded, resulting from the political and economic problems of the neighbouring Eastern countries. These new residents supplement the built structure of the existing settlements. Extension, completion and modernization of the existing settlements become evident also with the decentralization of urban population, which at the same time supply the new sectors of employment, besides agriculture. The historical facts that were mentioned before and the demographic change, diversify the structure and physiognomy of each settlement as it is represented in the architecture of the built form.

\section{Built form}

The rural settlements (population inferior to 2000 residents) of the Serres district can be classified in four categories according to the particular origin and 
condition of their implementation. The settlements that existed in 1923, represent the $25 \%$ of the current hundred twenty two settlements (122), the ones planned between 1923 and 1940 the 50\% (Fig.1), the planned after 1945 the $24 \%$ and the "Arbitrary" after 1970 the 1\%. The morphology of land distribution between these settlements is distinct according to their origin. In the surrounding mountains that delimit the district the older settlements are distributed, while the newer settlements, that followed the land reclamation and irrigation infrastructure of the plain are distributed along the river Strymon. The most recent ones are developed at length of road axes or in places where is expected a certain tourist development.

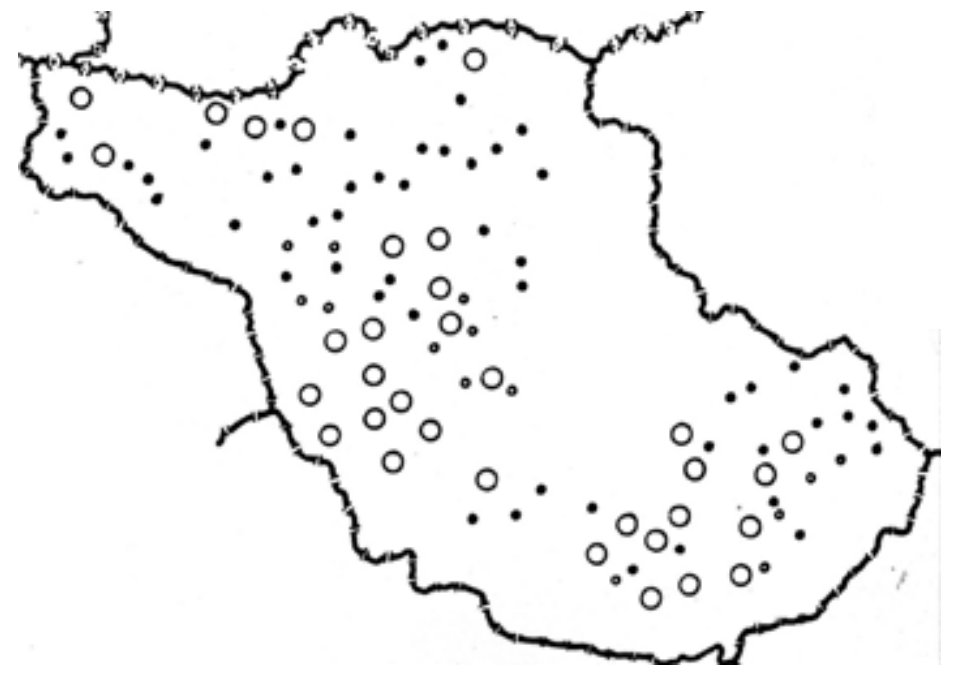

Figure 1: $\quad$ Settlements planned between 1923 and 1940: $\bullet$ New settlements for the refugees $\bigcirc$ New settlements for the implosion of dispersed population.

The structure of the settlements is represented by the existing "natural" or implemented "systematic" distributions starting in 1923. Irregular or regular forms or even a combination of the two, a fact that also correspond, in the agricultural morphology that surround each settlement. In four dimensions -in the architecture of buildings- differentiation exists between the architectural elements of each category of settlements. By examining aerial photographs the origin period is ascertained for each rural settlement. The existing before 1923 settlements and the surrounding exploitations, are based on natural distributions and follow the natural characteristics and topography of ground. In opposition, the settlements that were designed for the installation of refugees after 1923 follow the systematic distributions of the Ministry of Agriculture, not only for the settlement but also for the agricultural exploitations. 


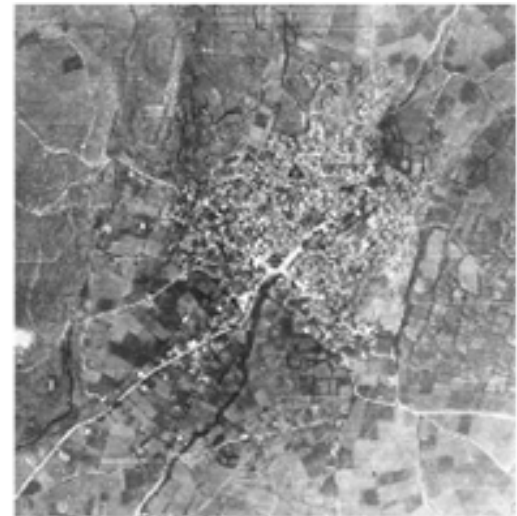

1

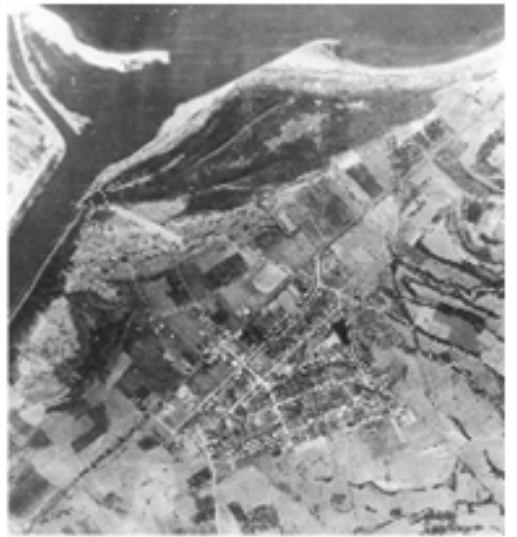

3

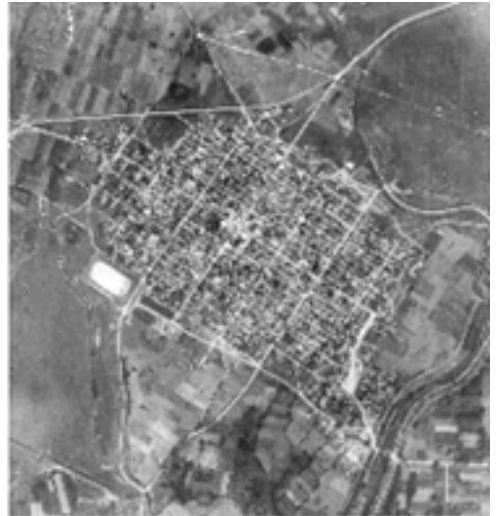

2

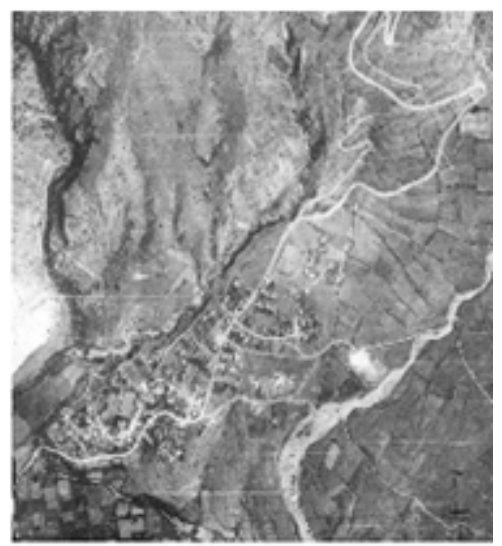

4

Figure 2: (1) Existing in 1923, (2) Planned in 1923, (3) Planned in 1945, (4) "Arbitrary" 1970.

The settlements, that were designed after 1945 follow freer distribution than that of the orthogonal "hyppodamian" one, and most of the time they were placed along the national roads. In contrast "arbitrary" settlement by 1970 follows the natural characteristics of the land and has the equivalent natural form, relative to the existing rural settlement in 1923 .

The archaeological discoveries sketch out the origins of the existing before 1923 settlements, from antiquity, Byzantine and Ottoman period. The new settlements that were planned on the district annexation to Greece and up to 1940, are classified to those that were designed specifically for the refugees, those that had to settle scattered population and those that were planned between 1930 and 1940. After 1945, the new settlements planned had to replace destroyed or abandoned ones during the War and were planned in order to serve the development of transports and rural industries. They are placed along the 
national road network. Few settlements were developed without preexisting design, by "arbitrary" settlement of residents which abandoned mountainous areas in order to settle near in the plain.

In the total of settlements of Serres district, the $83 \%$ constitute settlements with population inferior to 2,000 residents, meaning that it is counted as rural population. From them, the $33 \%$ has population inferior to 500 res., the $33 \%$ between 500 and 1.000 res., the $20 \%$ between 1.000 and 1.500 res. Only the $14 \%$ has a population close to 2,000 residents.

\section{Evolution of identity}

Diversity is defined by a series of attributes that are related to the uniqueness, the diversity, the functionality and the cohesion of a form of structure. The logic of local architectural diversity is established within the frame of evolutionary theory and follows the methodology that classifies built form according to geographical units, in order to distinguish the typological differences. The word classification suggests the arrangement of objects under congenial categories and it is the law of evolutionary process in biology conveyed (Picon [10]) in architecture.

Local typology in authentic architecture is developed along many centuries and composes the visible organization at the particular moment of observation. For the certification of distinct types, three stages (Gould [11]) of development (beginning, duration and destruction) must be completed. The particular architectural elements that determine a distinct identity document the stages of its historical path-way evolution. The particular architectural characteristics contribute in the distinct physiognomy of each settlement. In all places, the intercross of cultures endowed architectural types. In the Serres district the Byzantine and Ottoman typology is printed in the monuments as much as in the double typology of residences (opened or enclosed plan) (Theodoraki-Patsi [12]) of rural settlements before the 19th century heritage as it happened in all of Greece with exception of the parts that were under Latin occupation.

From the beginning of 20th century, the effect of neoclassicism symmetry is recorded in the design of the rural residences, which constitutes the late echo of the international movement of European romanticism and which found an organic correlation at the reconstruction of Greece. The residences that were designed from 1923 and onwards followed the model of various services, designed by engineers and architects that were educated according to the modern movement initiatives. Objective of this drawings was the protection of architectural local characteristics, that turned out in summary to the design of a simple rectangular plan covered with a pitched roof'. In the settlements planned after 1945, even though studies proposed updated houses designs based on the local traditional elements, in fact there were built versions of the urban multi story apartment buildings of the period interpreted in one or two floor.

After the first quarter of the 20th century, in the Serres district the evolutionary scheme for architecture, was confused with the Greek origin of the internationalism of neoclassicism. At the end of 20th century respectively the 
same confusion is strengthened by modern movement internationalism and recrudescent to the search of local traditional diversity.

Authentic rural architecture in the Serres district is saved in the mountain or foothill settlements and is represented in general by a long narrow form of two or three story houses with a storage room on the ground floor and living quarters upstairs. The latter consists of three rooms, in two typical representations. The lower walls were constructed of stone while the upper level was mud brick or woven willows plastered over with mud and manure. Houses were generally built in rows, with a veranda or balcony facing to an interior courtyard (Fig. 3).
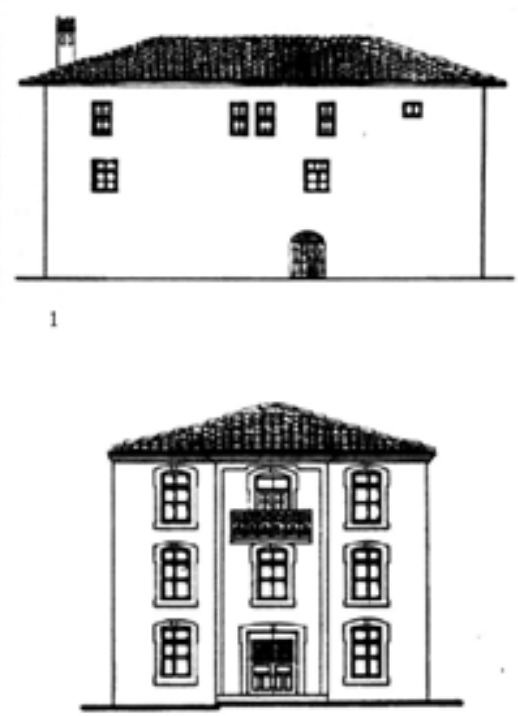

3
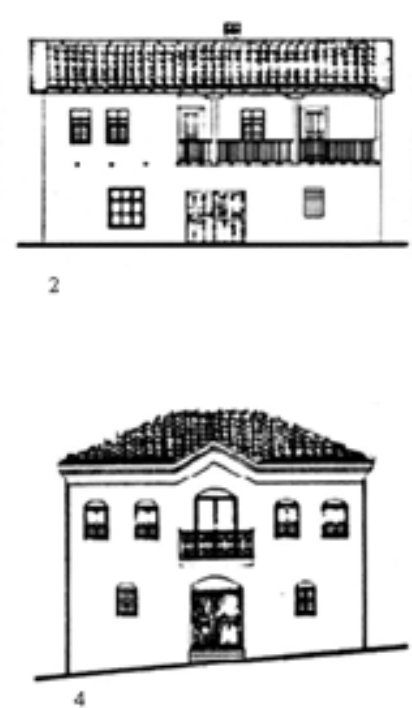

Figure 3: (1) Traditional rural residence of an "enclose" typology, 1800. (2) Traditional rural residence of an "open" typology, 1830. Neoclassical symmetry in rural residence, 1905. (4) Neoclassical symmetry in rural residence, 1905.

The arrival of 70,000 refugees accentuated a housing shortage already rendered serious from extensive war damage. Abandoned Turkish housing while helpful in settlement was in short supply. In many cases the houses were in such poor condition that it was more practical to convert the barn into a dwelling and relegate the house to a stable. Temporary shelter was provided through the use of tents and further overcrowding of abandoned buildings. Plans were drawn up for several housing styles with local materials which in most cases meant mud brick. The simplest style consisted of a single room with a small kitchen attached.

Since the speed of construction depended on the available labor and many refugees were unemployed, the C.R.R. allowed the refugees the option to build their own homes providing some elementary tools (wood, tiles, nails). By 1933, 
$90 \%$ of the refugees were housed but ethnic differences between natives and refugees became at first a critical factor in house hybridity. During this phase that continued up to the mid 20th century, while the purpose was to give accent to local traditional architecture, the poor economic support resulted mostly to transient constructions that did not survive. The settlements had since developed following different principles, following the institutional context and building code introduced.

The extensive destruction of the 2nd World War and the civil war greatly reduced the number of traditional houses remaining and triggered a building boom which transformed the image of many villages. These new houses were of a design homogenous throughout Greece, one or two story brick houses covered with plaster and a plain roof.

In the existing villages the building pattern has maintained its traditional character and the equivalent natural or systematic plans according to the time of settlement establishment until the beginning of the last quarter of the 20th century (a period of population concentration in urban centres), when many rural settlements have been declined or even abandoned. Thenceforth, parallel to a policy of decentralization, the development of building construction in rural settlement increased and began to expand beyond their boundaries. In an effort to protect the architectural identity, a building code was applied based once more on the diversity of traditional architectural elements for each settlement.

Authentic villages in the Serres district that were inherited from the Ottoman occupation period were developed incrementally as one house was attached to another, in a long period of time leading to a natural distribution of streets. Narrow and irregular streets pattern protected the houses from the acute climatic conditions (sun, wind) while the dense housing pattern was leaving more land for cultivation.

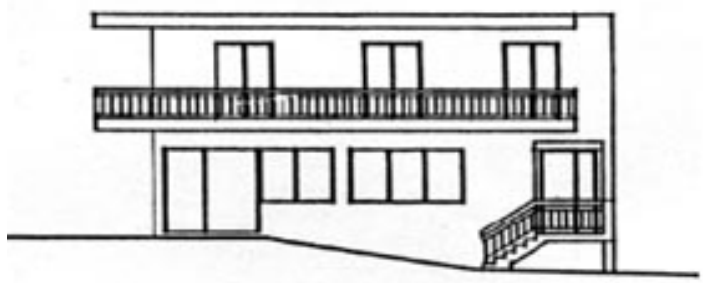

1

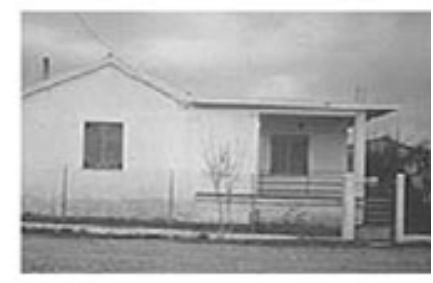

2

Figure 4: (1) Modern rural residence, 1980. (2) Intercross of traditional pitched roof with modern plain one.

\section{Conclusion}

Population movement is a transformation force for the places that becomes the loci (Norberg-Schulz [13]) of that flow. New identities and cultural formations emerge from the attitude of a new population: hybrid identities and ethnic 
enclaves. In many cases a loss of identity entails, a struggle to preserve heritage or the invention of a new heritage.

In summary, the following series of events happened in Serres. Between 1923 and 1945, an immense settlement program was implemented after a complete destruction of the region due to the First World War. Minimal authentic elements were maintained before that event in the existing villages that supported the term of tradition. The new villages were designed according to the ideas of new towns with the use of some minimal traditional elements of the wider Greek space, introducing symmetry and neoclassical symbolism. During this period, a first phase of hybridity was recorded in the area. Between 1945 and 1980, the modern style was in predominance resulting to the model house for the villages as in every part of the country to become a "slice" of block of flats that was the urban practice in favor. A second phase of hybridity was developed intercrossing the traditional elements with the modern ones (Fig. 4). The last 20 years, a revival of the search for the traditional culture is expressed and a return in the roots by the search of the authentic and the local identity issue. Recently, a new phase of hybridity has emerged under the instant communication of the global culture based on information technology projecting multi-culture phenomena.

In modern period the international tendency in architecture give accent in the tradition and in the particular architectural characteristics of each place in order to reinforce or to attribute a distinct identity. It is considered that in present times the human need for the particularity and the local differentiation, as this is represented in the built environment, acts as a key element for local and sustainable development (local, economic and environmental).

What happened to the rural regions until the recent explosion of information technology was completed in the urban centres previously. The case in rural areas is that in some cases, they did not have the time to complete the previous phase. To be able to understand how such a discourse is indeed a recurrence of what happened in the early modernist era, one must frame it within the context of the rise of the organized dichotomy between two types of societies, the rural and the urban.

In general, Greek architecture has evolved through neo-classical representation on one hand and on the other, with the use of traditional architectural elements. By the same period that other countries had to incorporate neoclassicism and later on the modern movement, as internationals styles, Greek architecture was context specific for both. Greek traditional architecture functioned as well as prototype -with the simple and cubist forms of Aegean sea architecture- for the masters of the modern movement. It seems that at least for Greek rural settlements (inhabitants less than 2,000), the contemporary built environment that the next generation will inherit is a fertile one. Evolution eventually will demonstrate the continuity of Greek architecture. From the point of view concerning the natural or systematic distribution of plots -that it is the clear distinction between traditional and planned patterns- the natural distribution is present in the majority of mountain settlements in rural areas, while systematic distribution is implemented in settlements situated mostly on the plains and in the extensions of urban centres. 
The evolution of Serres district is the result of an implementation project for rural development that followed in the span of a century different attitudes according to the socioeconomic period that Greece was experiencing in the context of the west view of what expressed modernization.

The interaction between rural environment, traditional architecture and new values produced successive hybrid built environment, that each time a new era was deconstructing, nevertheless resulting in a unique environment (even if improvements must continuously been implemented) embracing local values.

If today the issue is to invoke the heritage of the built environment it must be examined the process by which local identity has not to be ignored, distorted or stereotyped. It has to record the hybridity forms emerged. The description and interpretation of previous eras is difficult and in support comes the contemporary communication networks and simulated spaces of virtual representations as a key instrument for the transmission of tradition on the act of place making. Through web-site archives (Neo Souli [14]) that are created the memories of a place identity is protected for current and future use in a prospect of sustainable development.

Sustainable development is about safeguarding the capacity of a region to support life in all its diversity because homogenisation in the long run, works against it. In order to support diversity, institutions and intervention strategies adapted to the identity of each place are requested. In Greece the stuffing of Authorities concerned is limited and distributed between Ministry of Environment, Regional Planning and Public Works and Ministry of Culture that are in a constant overlapping and confronting policy. As a last conclusion, for the issue of sustainable development for 2007, it is essential to mention the necessity for establishing a better and comprehensive network of authorities concerned with the authenticity, hybridity and identity of each place and especially in rural space, where reinforcement of the identity becomes the framework for maintenance and rehabilitation of traditional architecture, in order to improve living conditions.

Epitomizing, the particular architectural characteristics of the Serres district are the result of interaction of traditional, neoclassic and modern architecture in a space where multi-destruction was experienced in the span of a century. In the present global post-modern/post- traditional period, it is necessary to safeguard and protect the particularity of the district and give time to the present architectural configuration with all the hybridity contained to evolve.

\section{References}

[1] Oliver, P., (ed.), Enc. of vernacular architecture of the world, University Press, Cambridge, p.33, 1997. [2]

[2] Gould, S., J., The structure of evolutionary theory, Belknap Press, Cambridge, p.132, 2002.

[3] As stated in the introduction of the Conservation of the architectural heritage of the Council of Europe, signed on 3.10.1985 in Granada, Spain. 
[4] www.rehabimed.net, Method for the rehabilitation of Traditional Mediterranean architecture, working document, p.9, 2005.

[5] Yeager, R., Refugee settlement and village change, 1912-1940, Doctoral Thesis, University of Pennsylvania, p. 93-98, 1975.

[6] Abott, G., B., The tale of a tour in Macedonia, Arnold, E., London, p. 32, 1903.

[7] Psathas, A., Popular history of Serres, Zichnali, Serres, p. 51, 1976.

[8] Bouazoglou, A., Contribution a l'etude l' economie rurale de la grece, Doctoral Thesis, University of Nancy, p. 39, 1931.

[9] Ministry of Transport (ed), Extracts of studies \& drawings of settlements etc, Athens, 1930.

[10] Picon, A., Architecture, science, technology and the virtual realm, in Picon A., Ponte A., (eds), Architecture and the sciences, Princeston Architectural Press, 2002, p.295, 1996.

[11] Gould, S., J., The structure of evolutionary theory, Cambridge, Belknap Press, p. 602, 2002.

[12] Theodoraki-Patsi, J., Rural settlements: The case of Serres District, Athens, Doctoral Thesis, E.M.P, 1997.

[13] Norberg-Schulz, Chr., Genius Loci: Towards a Phenomenology of Architecture, Rizollo, 1970.

[14] Web site: neo souli 15.12.2006, http:/gym-n-souliou.ser.sch.gr/ efimerida_en.htm 